\title{
A novel compound against oncogenic Aurora kinase A overcomes imatinib resistance in chronic myeloid leukemia cells
}

\author{
ZI-JIE LONG ${ }^{1 *}$, LE-XUN WANG $^{1 *}$, FEI-MENG ZHENG ${ }^{2,3}$, JIA-JIE CHEN $^{1}$, \\ YU LUO ${ }^{4}$, XI-XIANG TU ${ }^{3}$, DONG-JUN LIN ${ }^{1}$, GUI LU ${ }^{4}$ and QUENTIN LIU ${ }^{1-3}$

\begin{abstract}
${ }^{1}$ Department of Hematology, The Third Affiliated Hospital, Sun Yat-sen University, Sun Yat-sen Institute of Hematology, Guangzhou 510630; ${ }^{2}$ State Key Laboratory of Oncology in South China, Sun Yat-sen University Cancer Center, Guangzhou 510060; ${ }^{3}$ Institute of Cancer Stem Cell, Dalian Medical University, Dalian 116044;
\end{abstract} \\ ${ }^{4}$ Institute of Medicinal Chemistry, School of Pharmaceutical Sciences, Sun Yat-sen University, Guangzhou 510006, P.R. China
}

Received July 11, 2014; Accepted January 20, 2015

DOI: $10.3892 /$ ijo.2015.2960

\begin{abstract}
Drug resistance still represents a major obstacle to successful chronic myeloid leukemia (CML) treatment and novel compounds or strategies to override this challenging problem are urgently required. Here, we evaluated a novel compound AKI603 against oncogenic Aurora kinase A (Aur-A) in imatinib-resistant CML cells. We found that Aur-A was highly activated in imatinib-resistant KBM5-T315I cells. AKI603 significantly inhibited the phosphorylation of Aur-A kinase at Thr288, while had little inhibitory effect on BCR-ABL kinase in both KBM5 and KBM5-T315I cells. AKI603 inhibited cell viability, and induced cell cycle arrest with polyploidy accumulation in KBM5 and KBM5-T315I cells. Moreover, inhibition of Aur-A kinase by AKI603 suppressed colony formation capacity without promoting obvious apoptosis. Importantly, AKI603 promoted cell differentiation in both CML cell types. Thus, our study suggested the potential clinical use of small molecule Aurora kinase inhibitor AKI603 to overcome imatinib resistance in CML treatment.
\end{abstract}

Correspondence to: Professor Quentin Liu, Department of Hematology, The Third Affiliated Hospital, Sun Yat-sen University, 600 Tianhe Road, Guangzhou 510630, P.R. China

E-mail: liuq9@mail.sysu.edu.cn

Professor Gui Lu, Institute of Medicinal Chemistry, School of Pharmaceutical Sciences, Sun Yat-sen University, 132 Waihuan Road East, Guangzhou 510006, P.R. China

E-mail: lugui@mail.sysu.edu.cn

*Contributed equally

Abbreviations: CML, chronic myeloid leukemia; AML, acute myeloid leukemia; TKIs, tyrosine kinase inhibitors; LSCs, leukemia stem cells; TICs, tumor initiating cells; CBMCs, cord blood mononuclear cells

Key words: Aurora kinase A, small molecule inhibitor, chronic myeloid leukemia, differentiation, drug resistance

\section{Introduction}

Chronic myeloid leukemia (CML) is a clonal myeloproliferative neoplasm characterized by Philadelphia chromosome, the $\mathrm{t}(9 ; 22)$ (q34;q11) reciprocal translocation, resulting in the expression of BCR-ABL fusion protein (1). BCR-ABL is a tyrosine kinase responsible for malignant transformation by activating multiple signal pathways, including the PI3K/Akt, MAPK/ERK and STATs (2-4), leading to aberrant cell survival $(5,6)$. The successful introduction of the tyrosine kinase inhibitors (TKIs), constitutes an effective strategy in CML. The US Food and Drug Administration (FDA) has approved imatinib as the first-line treatment for Philadelphia chromosome-positive CML. Unfortunately, a portion of patients may relapse upon drug discontinuation, or drug resistance (7). Studies reported that different point mutations were associated with resistance to imatinib, and T315I mutation in BCR-ABL, was particularly frequent (8). To overcome imatinib resistance, second generation TKIs have been developed, such as dasatinib, nilotinib, bosutinib and bafetinib. However, the T315I mutation confers resistance to all these TKIs $(9,10)$. Hence, novel compounds or strategies to override this challenging problem are urgently required for CML treatment.

Aurora kinase A (Aur-A), an oncogenic protein of serine/ threonine kinases family, is central for mitotic progression (11). Aur-A was aberrantly overexpressed in solid tumors such as prostate, colon, pancreas, and breast cancer, as well as leukemia (12). Recent study suggested that Aur-A kinase activity was responsible for chemoresistance and tumorigenic ability (13). Small molecule kinase inhibitors of Aur-A have attracted great interest, such as MLN8237, ZM447439 and VX-680 (MK0457). VX-680 effectively inhibited multiple myeloma growth, especially in RHAMM overexpressing patients, and CML with BCR-ABL mutations (14-16). Recently, we synthesized and identified a novel compound against Aur-A termed AKI603 with $\mathrm{IC}_{50}=12.3 \pm 1.5$ $\mathrm{nM}$ in vitro by kinase activity assay. AKI603 inhibited breast cancer cell line proliferation, especially abolished enrichment of tumor initiating cells (TICs) induced by epirubicin, suggesting its potent use in solid cancer treatment (17).

In this study, we investigated the effects of the novel Aur-A small molecule inhibitor AKI603 in CML cells including 
imatinib-resistant cells. The results showed that AKI603 inhibited cell proliferation with $\mathrm{G} 2 / \mathrm{M}$ phase cell cycle arrest. Interestingly, imatinib-resistant cells displayed high Aur-A kinase activity, while targeting Aur-A kinase activity by AKI603 potently suppressed colony formation ability and promoted cell differentiation. Thus, inhibition of Aur-A kinase overcame imatinib resistance, providing a novel therapeutic strategy against CML.

\section{Materials and methods}

Chemicals and cell culture. AKI603, designed and synthesized by our lab $(17,18)$, was dissolved in dimethyl sulfoxide (DMSO) to a stock concentration of $100 \mathrm{mM}$ and stored at $-20^{\circ} \mathrm{C}$. Imatinib (Sigma-Aldrich, St. Louis, MO, USA) was dissolved in DMSO at $10 \mathrm{mM}$ stock solution and stored at $-20^{\circ} \mathrm{C}$. KBM5 and KBM5-T315I cell lines were gifts from Dr Peng Huang (MD Anderson Cancer Center, Houston, TX, USA). All the cells were cultured in RPMI-1640 medium supplemented with $10 \%$ (v/v) fetal bovine serum (Gibco, Invitrogen, Carlsbad, CA, USA). Cord blood mononuclear cells (CBMCs) were obtained from 3 healthy donors. All donors provided written informed consent, and the study was approved by the Institute Research Ethics Committee at Sun Yat-sen University.

Cell viability assay. Cell viability was evaluated by WST-8 assay (Dojindo Laboratories, Kumamoto, Japan) according to the manufacturer's instructions. Briefly, $1 \times 10^{4}$ cells were seeded in each well of the 96-well flat-bottomed plate. After treatment with imatinib or AKI603 for $48 \mathrm{~h}, 10 \mu \mathrm{l}$ WST-8 solution was added to each well and cells were incubated at $37^{\circ} \mathrm{C}$ for $4 \mathrm{~h}$. The absorbance was finally determined at 450 $\mathrm{nm}$ using an Eon Microplate Spectrophotometer (BioTek, Winooski, VT, USA).

Cell cycle analysis. Cells were collected, fixed, and resuspended in PBS containing $0.2 \%$ Triton X-100, $100 \mu \mathrm{g} / \mathrm{ml}$ RNaseA, and $50 \mu \mathrm{g} / \mathrm{ml}$ PI. Cell cycle analysis was carried out using a FACSCalibur flow cytometer (BD Biosciences, San Jose, CA, USA).

Cell differentiation assessment. To measure CD11b expression, cells were treated with indicated concentration of AKI603. After culture, cells were collected and incubated with PE-CD11b antibody (BD Biosciences). Expression of $\mathrm{CD} 11 \mathrm{~b}$ on cell surface was measured by flow cytometry.

Colony formation assay. Cells were cultured in RPMI1640 medium supplemented with $0.9 \%$ methylcellulose and $10 \%$ FBS. The colonies (containing $\geq 40$ cells) were counted by light microscopy after 10 days.

Western blot analysis. Total cellular proteins were isolated with lysis buffer. Equal amounts of protein were subjected to SDS-PAGE and transferred to nitrocellulose membranes. The membranes were blocked and then incubated with phosphoAur-A, phospho-c-Abl, pRb, Rb (Cell Signaling Technology Corp., Beverly, MA, USA), Aur-A (Sigma-Aldrich), c-Abl and GAPDH antibodies (Santa Cruz Biotechnology, Santa Cruz, CA, USA). The protein bands were visualized using an enhanced chemiluminescence reagent (Sigma-Aldrich), according to the manufacturer's instructions.

Annexin V/PI analysis. Cells were treated with the indicated concentration of AKI603, collected and resuspended in the binding buffer. Annexin-V-FITC and PI was added to the cells according to the protocol by the Annexin V-FITC apoptosis detection kit (BD Biosciences). The cells were then incubated for $15 \mathrm{~min}$ in the dark and subjected to flow cytometry analysis.

Cell morphology analysis. Cells were incubated with AKI603 for the indicated dose and collected for analysis. Cytospin slides were prepared, and the cells were counterstained with Wright-Giemsa. The morphology of cells was observed by microscopy (IX81, Olympus, Japan).

Nitrotetrazolium blue chloride (NBT) reduction assay. The same amount of cells untreated or treated with AKI603 were incubated at $37^{\circ} \mathrm{C}$ in RPMI-1640 medium containing $10 \% \mathrm{FBS}$ and $0.1 \%$ NBT (Sigma-Aldrich). The cells were then centrifuged and dissolved in DMSO. The optical density was read at $570 \mathrm{~nm}$.

Statistical analysis. Data are presented as mean \pm SD. Statistical analysis was performed using SPSS version 16.0 (SPSS, Inc.) and Prism 6 (GraphPad Software, Inc.). The Kruskal-Wallis test, followed by Dunn's multiple comparison test, was used to perform statistical comparison for colony size distribution. The unpaired Student's t-test was used to perform statistical comparison between two groups. The ANOVA test, followed by least significant difference test, was used for multiple comparisons. A value of $\mathrm{p}<0.05$ was considered statistically significant.

\section{Results}

AKI603 inhibits Aur-A activity and cell viability in CML cells. Chemical structure of AKI603 is shown in Fig. 1A. In this study, we applied two CML cells lines, KBM5 and imatinibresistant KBM5-T315I cells to study the effects of AKI603. WST-8 assay showed that KBM-T315I cells exhibited significant resistance towards imatinib compared with the wild-type KBM5 cells (Fig. 1B). To evaluate CML cell proliferation by AKI603 treatment, cell viability was also assessed by WST-8 assay. The CML cell lines tested were sensitive to AKI603 ranging from 0.3125 to $5.0 \mu \mathrm{M}$ (Fig. 1C). In $0.3125 \mu \mathrm{M}$ treatment, the cell viability was decreased to $68.8 \pm 1.6 \%$ in KBM5 cells and $78.2 \pm 3.0 \%$ in KBM5-T315I cells. In $5.0 \mu \mathrm{M}$ treatment, the cell viability was decreased to $25.0 \pm 1.4 \%$ in KBM5 cells while $40.7 \pm 0.9 \%$ in KBM5-T315I cells. Moreover, mononuclear cells from cord blood were exposed to various concentrations of AKI603. Results showed that cell viability was slightly changed after 48-h incubation (Fig. 1D). To assess whether AKI603 inhibited Aur-A kinase activity, western blot analysis was performed. As shown in Fig. 1E, KBM-T315I cells displayed high level of Aur-A Thr288 phosphorylation. Treatment with AKI603 for 48 h significantly inhibited Aur-A phosphorylation (labeled pAur-A) at $0.3125 \mu \mathrm{M}$ or higher concentrations in KBM5 and KBM5-T315I cells, while total Aur-A protein was not changed. Moreover, we detected the change of BCR-ABL phosphorylation (labeled pBCR-ABL) 
A

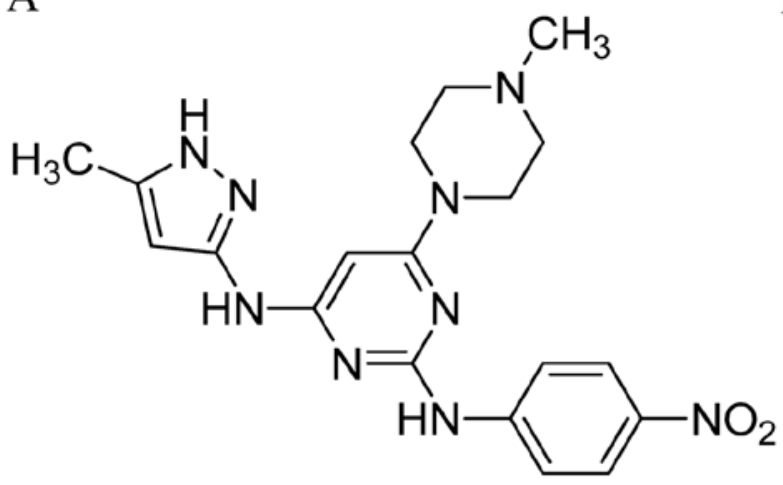

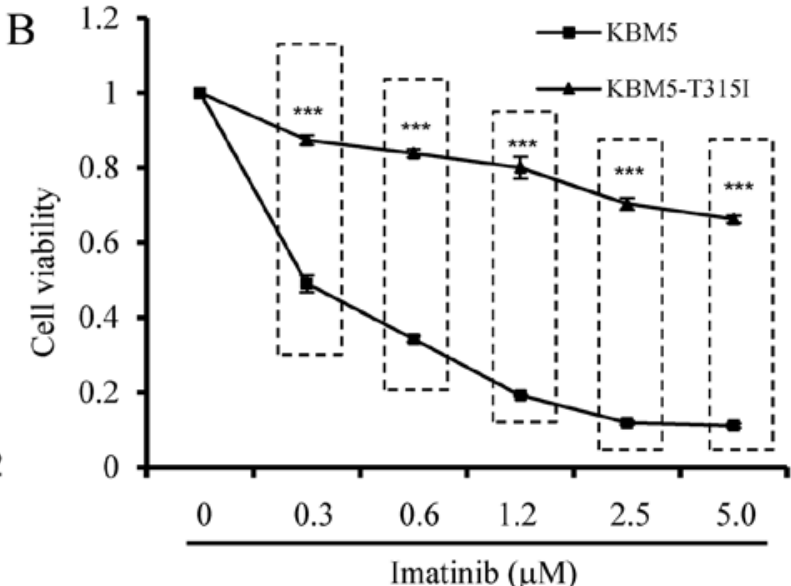

.

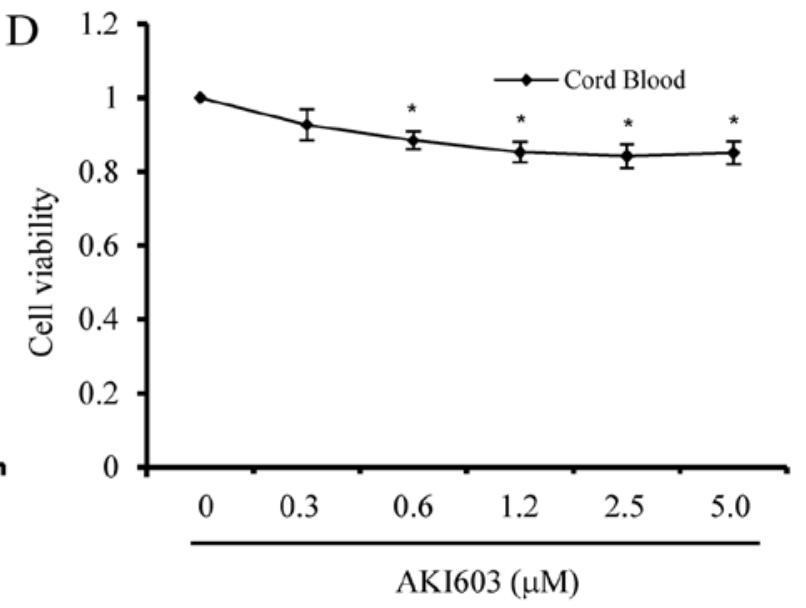

AKI603 $(\mu \mathrm{M})$

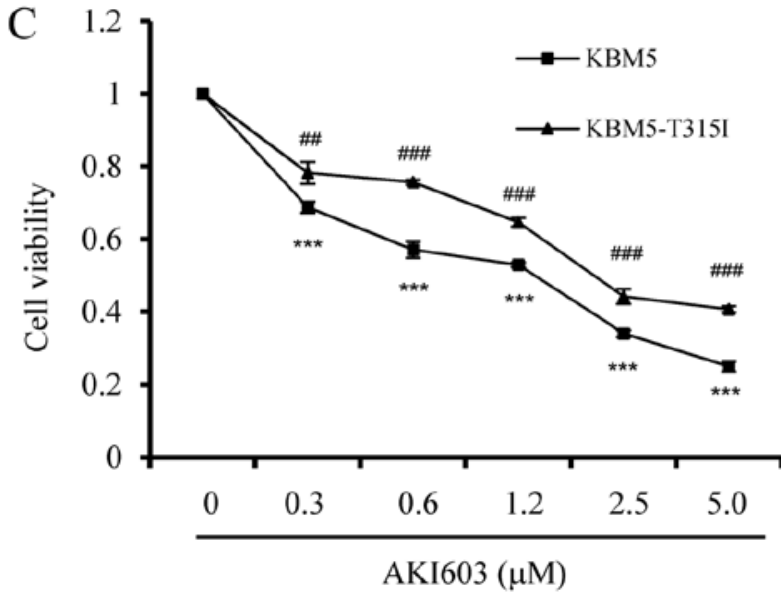

E KBM5-AKI603 $(\mu \mathrm{M})$ KBM5-T315I-AKI603 $(\mu \mathrm{M})$
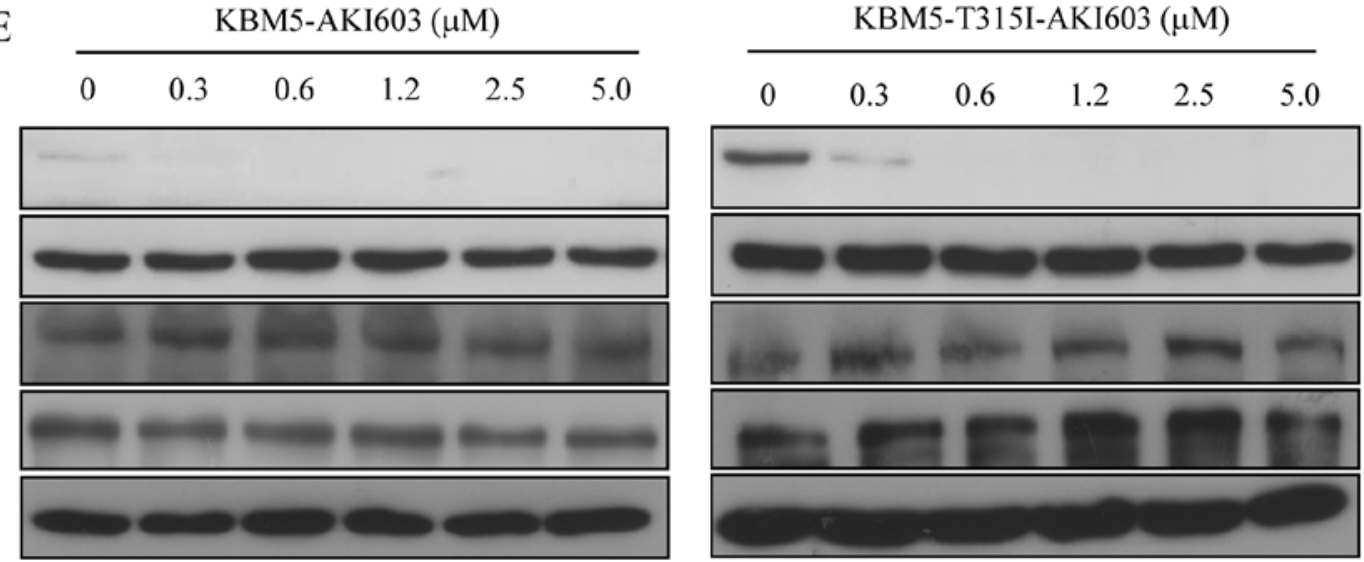

pAur-A

Aur-A

pBCR-ABL

BCR-ABL

GAPDH

Figure 1. AKI603 inhibits Aur-A activity and cell viability in CML cells. (A) Chemical structure of AKI603. (B) KBM5 and KBM5-T315I cells were treated with different doses of imatinib for $48 \mathrm{~h}$ and subjected to WST- 8 assay. Data are the mean of three independent experiments ${ }^{* * *} \mathrm{p}<0.001$, Student's t-test). (C) Cells treated with various concentrations of AKI603 for $48 \mathrm{~h}$ were subjected to WST- 8 assay. Data are the mean of three independent experiments $\left({ }^{* *}\right.$ or ${ }^{\# \#} \mathrm{p}<0.01,{ }^{* * *}$ or ${ }^{\# \# \#} \mathrm{p}<0.001$. The ANOVA test, followed by least significant difference test, was used for statistical comparison). (D) CBMCs of three healthy donors were exposed to different concentrations of AKI603 for $48 \mathrm{~h}$. WST-8 assay was performed. (E) Cells were treated with various concentrations of AKI603 $(0,0.3125,0.625,1.25,2.5$ and $5.0 \mu \mathrm{M})$ for $48 \mathrm{~h}$. The lysates were subjected for western blot analysis of pAur-A (active form), Aur-A, pBCR-ABL (active form) and BCR-ABL expression.

after AKI603 treatment. We found that either phosphorylation or total protein of BCR-ABL was stable in different treatments of AKI603, ruling out the possibility that the effect of AKI603 was through inhibition of BCR-ABL activity. Our data implied that AKI603 might have a potential therapeutic application in leukemia treatment.
AKI603 induces cell cycle arrest and decreases Rb phosphorylation in CML cells. Due to the crucial role of Aur-A in mitosis, the cell cycle blocking effect on KBM5 and KBM5-T315I was examined. AKI603 significantly induced polyploidization in CML cells as assessed by microscopy observation (Fig. 2A). These morphological changes were 
A $\quad$ KBM5
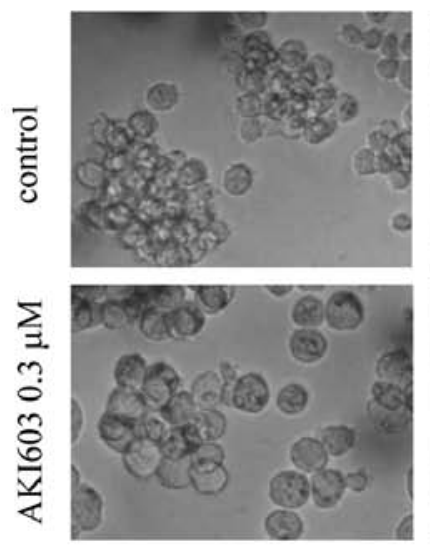

KBM5-T315I

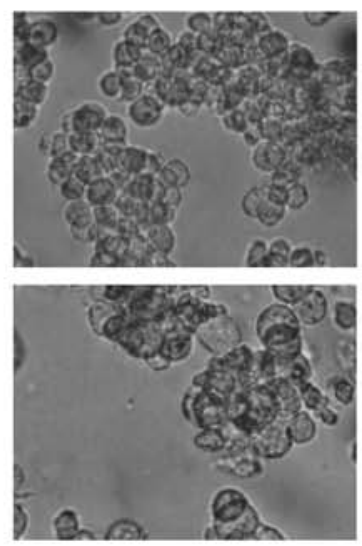

B
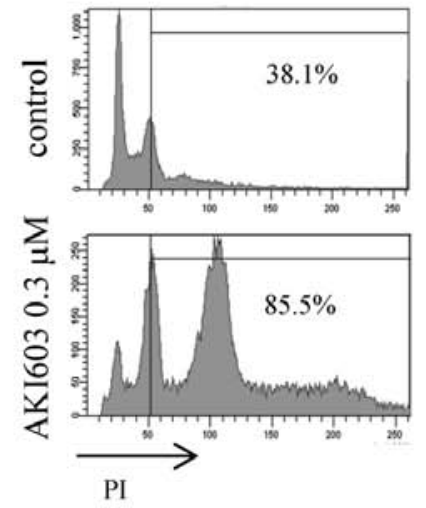

KBM5-T315I
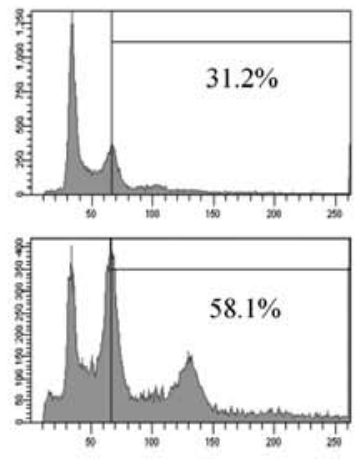

C

KBM5-AKI603 $(\mu \mathrm{M})$
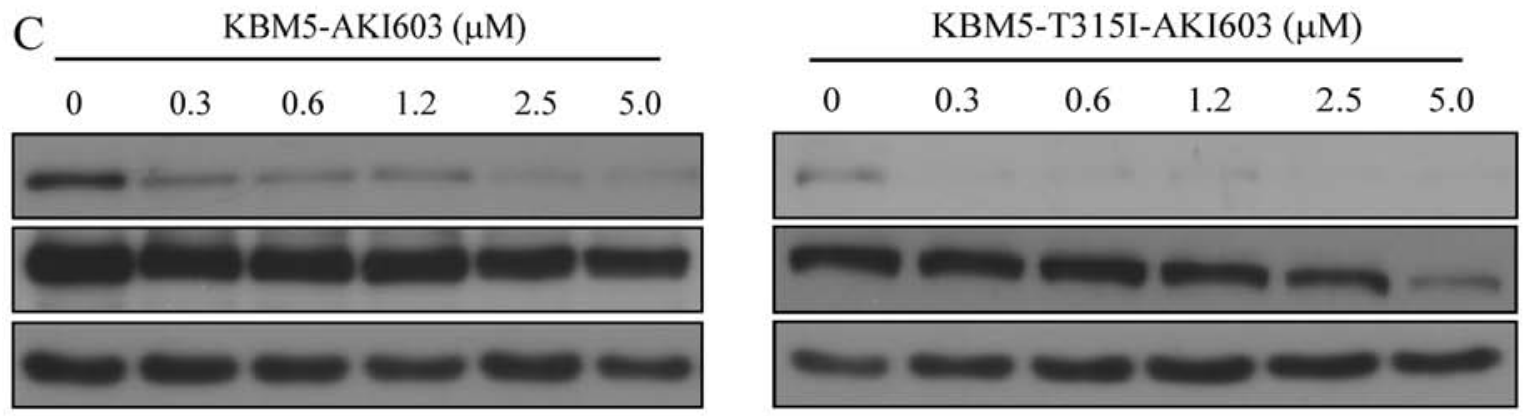

$\mathrm{pRb}$

$\mathrm{Rb}$

GAPDH

Figure 2. AKI603 induces cell cycle arrest and decreases Rb phosphorylation in CML cells. (A) KBM5 and KBM5-T315I cells were treated with indicated concentration of AKI603 for $48 \mathrm{~h}$. Morphological changes were observed under microscopy (magnification, x400). (B) Cell cycle was analyzed by flow cytometry. (C) Cells were treated with indicated concentrations of AKI603 for $48 \mathrm{~h}$. Then, cells were collected and subjected for western blot analysis for expression of $\mathrm{pRb}, \mathrm{Rb}$ and $\mathrm{GAPDH}$.

confirmed by flow cytometry. DNA content analysis by PI staining showed that treatment of AKI603 induced polyploidy of both KBM5 and KBM-T315I cells (Fig. 2B). These results suggested that the proliferative inhibition induced by AKI603 could be associated with cell cycle blockage. In addition, western blot analysis showed that phosphorylation of $\mathrm{Rb}$ was reduced in AKI603 treated cells, even at the concentration of $0.3125 \mu \mathrm{M}$ (Fig. 2C). Thus, our data suggested that AKI603 might inhibit cell proliferation by inducing $\mathrm{G} 2 / \mathrm{M}$ cell cycle arrest, and reducing $\mathrm{Rb}$ phosphorylation.

AKI603 does not induce obvious apoptosis in CML cells. To evaluate whether AKI603 induced apoptosis, cells were collected for flow cytometry analysis of Annexin V/PI staining. As shown in Fig. 1, $0.3125 \mu \mathrm{M}$ AKI603 significantly suppressed cell viability, thus we chose this concentration for apoptosis detection. The results showed that both KBM5 and KBM5-T315I cells treated with indicated concentration $(0.3125 \mu \mathrm{M})$ of AKI603 did not undergo obvious apoptosis either in 48 or 96 h (Fig. 3A). In 96-h treatment, AKI603 increased the percentage of apoptotic cells from $8.6 \pm 1.3$ to $14.2 \pm 1.3 \%$ in KBM5 cells and from $7.1 \pm 0.4$ to $10.6 \pm 0.8 \%$ in KBM5-T315I cells (Fig. 3B), indicating that cell viability inhibited by AKI603 was not largely due to apoptosis.

AKI603 suppresses colony formation ability in CML cells. We next examined the long-term effect (10 days) of AKI603 against cell colony formation capacity. To this end, the two cell types were maintained in methylcellulose culture medium with or without different treatment, and the diameter and number of the colonies were measured. First, we investigated the longterm effect of the cells under imatinib treatment. As shown in Fig. 4A and B, $0.3125 \mu \mathrm{M}$ imatinib decreased the size of colony formation $(56.8 \pm 26.0 \mu \mathrm{m}, \mathrm{p}<0.001)$ compared with the control group $(206.7 \pm 69.2 \mu \mathrm{m})$ in KBM5 cells. However, $0.3125 \mu \mathrm{M}$ imatinib did not obviously decrease the size of colony formation in KBM5-T315I cells. The results further suggested that imatinib could not inhibit the cell colony formation capacity in KBM5-T315I cells. We next examined the long-term effect of AKI603. The colonies in AKI603 treatment groups were fewer than the control group. Under the concentration of $0.3125 \mu \mathrm{M}$, the cells could not form colonies in either cell type (Fig. 4C). Thus, we reduced the treatment concentration of AKI603 and found that $0.1563 \mu \mathrm{M}$ treatment completely suppressed the colony formation (Fig. 4D). Under low concentrations, the colony size was smaller when cultured with AKI603 compared with control (Fig. 4E and F). For example, $0.0781 \mu \mathrm{M}$ AKI603 decreased the size of colony formation $(112.8 \pm 44.7 \mu \mathrm{m}$, $\mathrm{p}<0.001)$ compared with the control group $(218.2 \pm 64.2 \mu \mathrm{m})$ in KBM5 cells. In KBM5-T315I cells, AKI603 decreased the size of colony formation $(169.8 \pm 70.7 \mu \mathrm{m}, \mathrm{p}<0.001)$ compared with the control group $(243.7 \pm 84.6 \mu \mathrm{m})$.

AKI603 promotes cell differentiation in CML cells. After 96-h incubation with AKI603, we found that both cell types presented polyploidization and obvious phenotype changes 
A
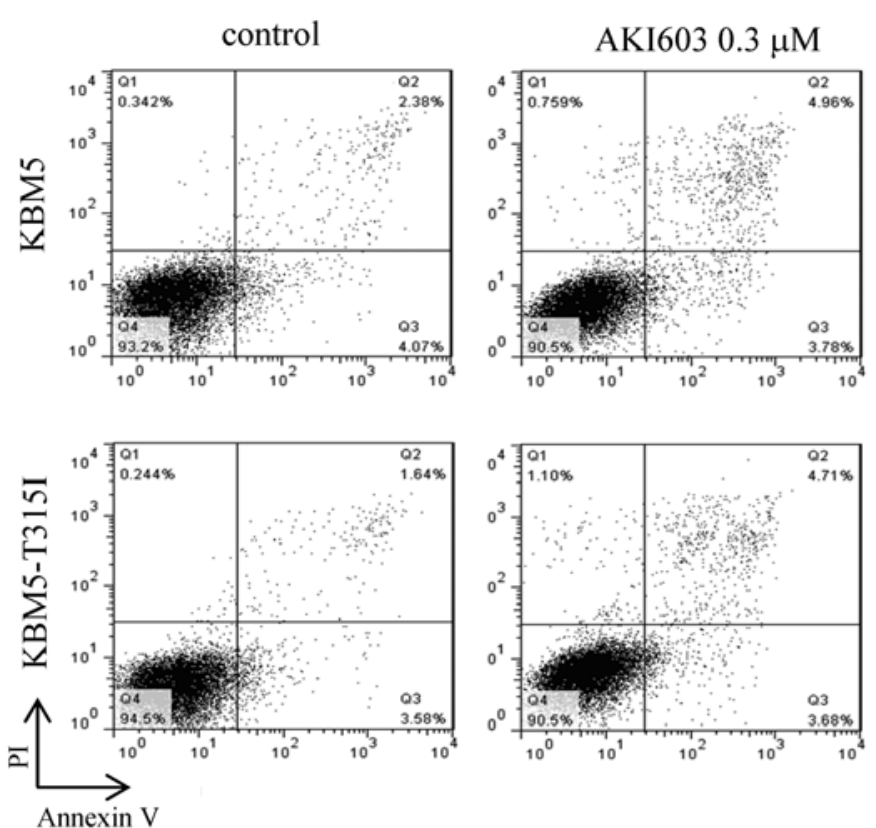

$48 \mathrm{~h}$
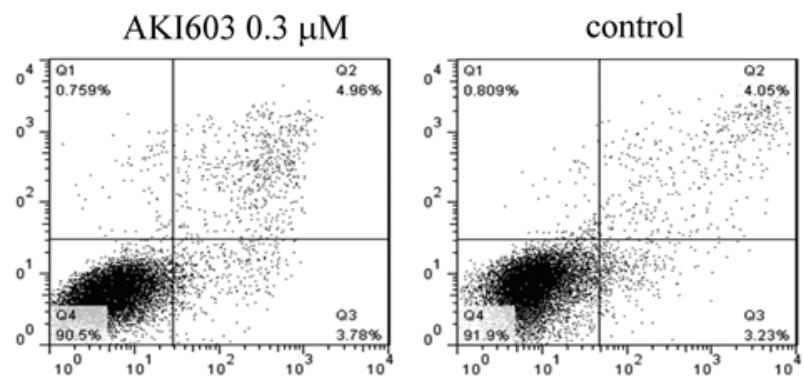

$96 \mathrm{~h}$

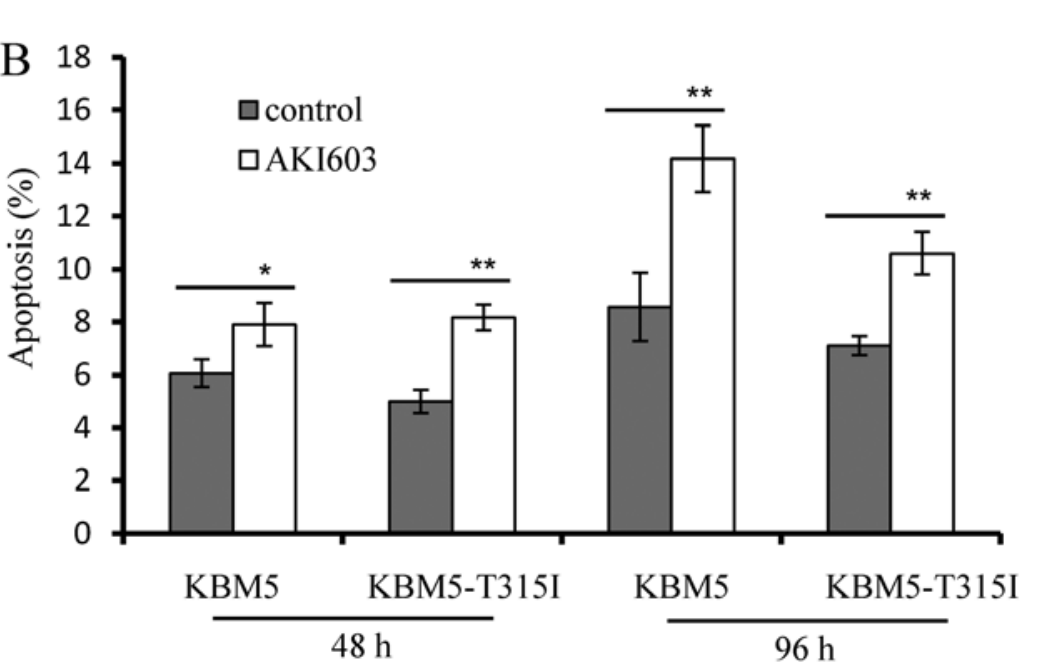

Figure 3. AKI603 does not induce obvious apoptosis in CML cells. (A) KBM5 and KBM5-T315I cells were treated with AKI603 for 48 or 96 h. Cells were then subjected for flow cytometry analysis with Annexin V/PI staining. (B) The statistical analysis of apoptosis is presented as a bar graph. The bar represents means \pm SD of three independent experiments $\left({ }^{*} \mathrm{p}<0.05,{ }^{* *} \mathrm{p}<0.01\right.$, Student's t-test $)$.

by Wright-Giemsa staining (Fig. 5A). To investigate the mechanism of AKI603 inhibition of colony formation without inducing apoptosis, the KBM5 and KBM5-T315I cells were treated with AKI603 and cell differentiation was evaluated by quantifying CD11b expression, a marker of myeloid differentiation. After exposure of KBM5 and KBM-T315I cells to AKI603 $(0.3125 \mu \mathrm{M})$ for $48 \mathrm{~h}$, the percentage of CD11bpositive cells induced by AKI603 was significantly increased from $4.0 \pm 0.2$ to $19.7 \pm 1.6 \%$ in KBM5 cells and from $8.1 \pm 0.8$ to $34.2 \pm 1.1 \%$ in KBM5-T315I cells. Moreover, 96-h treatment increased CD11b expression from $3.4 \pm 0.1$ to $61.7 \pm 2.4 \%$ in KBM5 cells and from $9.1 \pm 0.2$ to $56.7 \pm 1.0 \%$ in KBM5-T315I cells (Fig. 5B and C). The differentiation state was also confirmed by NBT reduction assay (Fig. 5D). Results showed that both cells displayed increased NBT reduction after AKI603 treatment, indicating the sensitivity of both KBM5 and KBM5-T315I cells to AKI603 might be due to induced cell differentiation.

\section{Discussion}

To date, imatinib represents a major success in the era of targeted cancer therapy. However, point mutation in BCR-ABL, which prevents imatinib binding, is responsible for most of the cases of acquired clinical resistance to imatinib. Different point mutations in the BCR-ABL kinase domain have been isolated from patients expressing $\operatorname{BCR}-\operatorname{ABL}(19,20)$. In addition to imatinib, other novel TKIs are also ineffective against the T315I mutation. Patients with T315I have a poor prognosis, with a short survival from the initiation of imatinib therapy $(21,22)$. Therefore, we aimed to identify effective targeted therapy against CML cells carrying the wild-type 

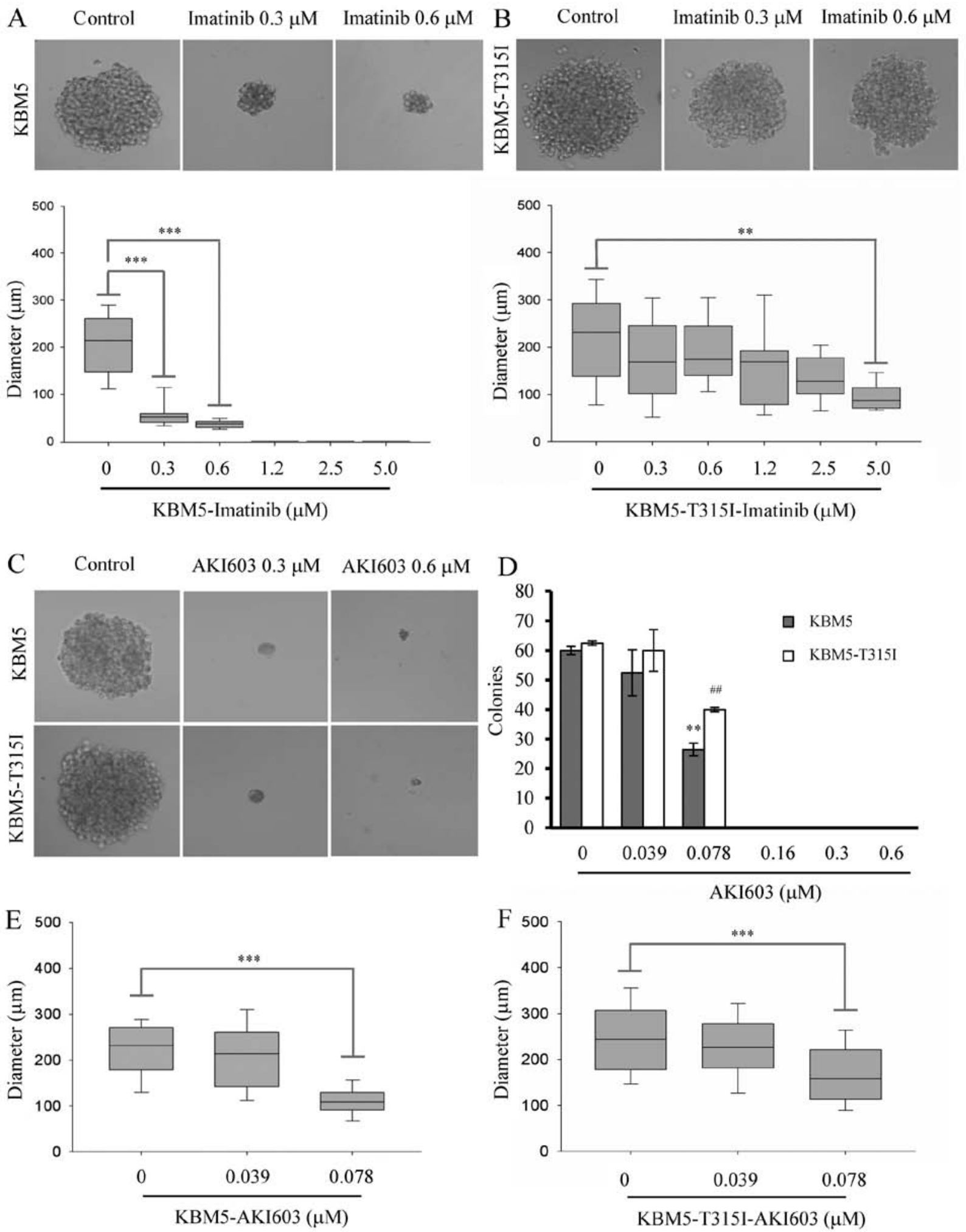

Figure 4. AKI603 suppresses colony formation ability in CML cells. The colony formation of KBM5 and KBM5-T315I cells treated with imatinib for 10 days were analyzed. Ten-day-old KBM5 (A) and KBM5-T315I (B) colonies cultured in medium containing indicated concentrations of imatinib were photographed. Representative images and the diameters of colonies are shown. The values from three independent experiments are presented in a box plot graph and the size distribution of the colonies is shown. The horizontal line within each box represent the median value. The Kruskal-Wallis test, followed by Dunn's multiple comparison test, was used to make statistical comparisons $\left({ }^{* *} \mathrm{p}<0.01,{ }^{* * *} \mathrm{p}<0.001\right)$. (C) The colony formation of KBM5 and KBM5-T315I treated with $0,0.0391$, $0.0781,0.1563,0.3125,0.625,1.25,2.5$ and $5.0 \mu \mathrm{M}$ of AKI603 for 10 days were analyzed. Representative images are shown. (D) The number of colonies is presented as a bar graph. The bar represents means \pm SD of three independent experiments. The diameters of 10-day-old KBM5 (E) and KBM5-T315I (F) colonies cultured in medium containing indicated concentrations of AKI603 were measured as described above $\left({ }^{* * *} \mathrm{p}<0.001\right)$.

BCR-ABL or BCR-ABL-T315I mutation. In the present study, we showed that novel small molecular inhibitor AKI603 effec- tively inhibited Aur-A kinase activity. Surprisingly, AKI603 potently inhibited cell proliferation, suppressed colony 


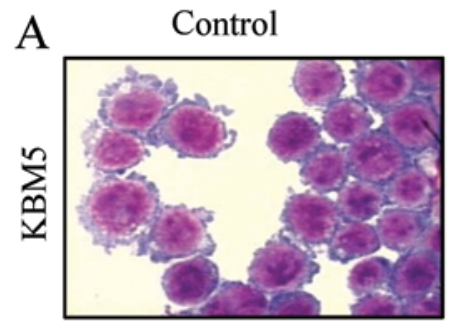

B
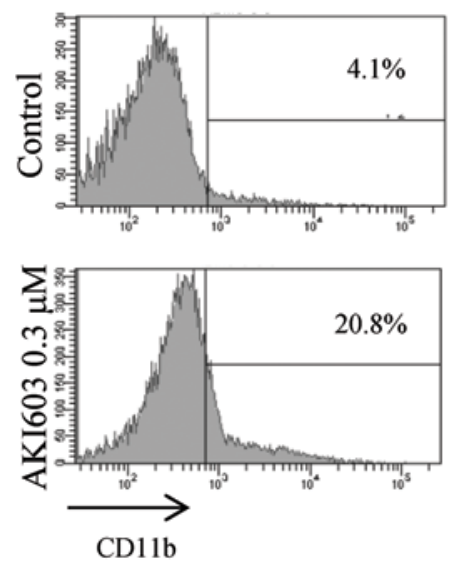

AKI603 $0.3 \mu \mathrm{M}$
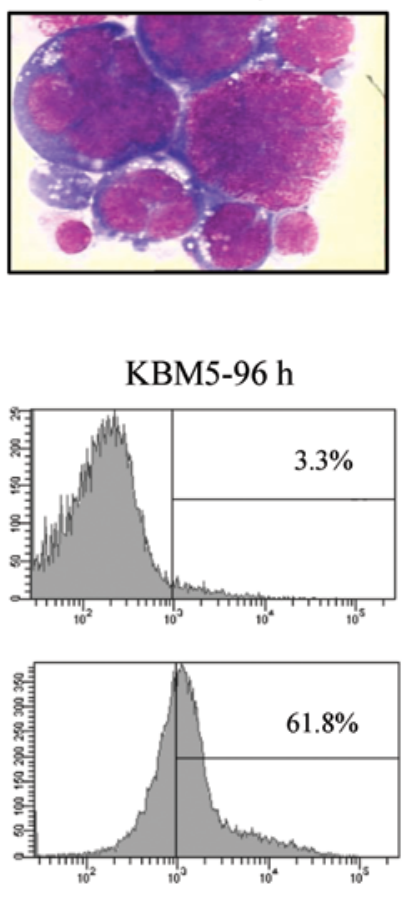

Control

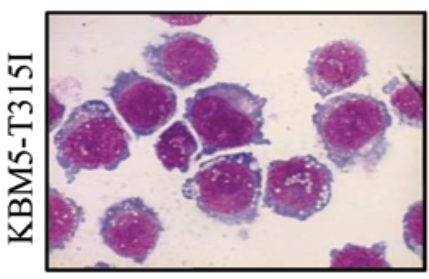

KBM5-96 h
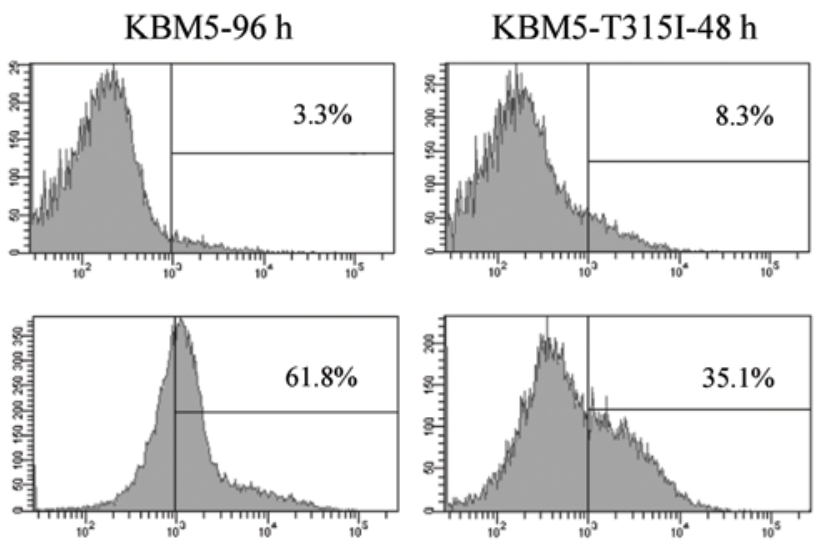

AKI603 $0.3 \mu \mathrm{M}$

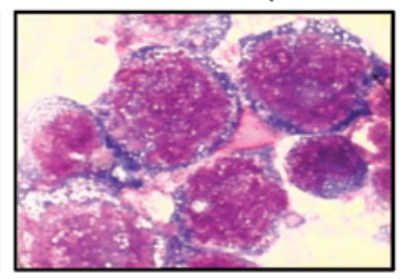

KBM5-T315I-96 h
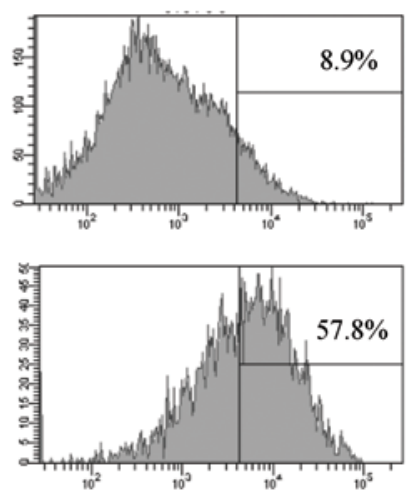
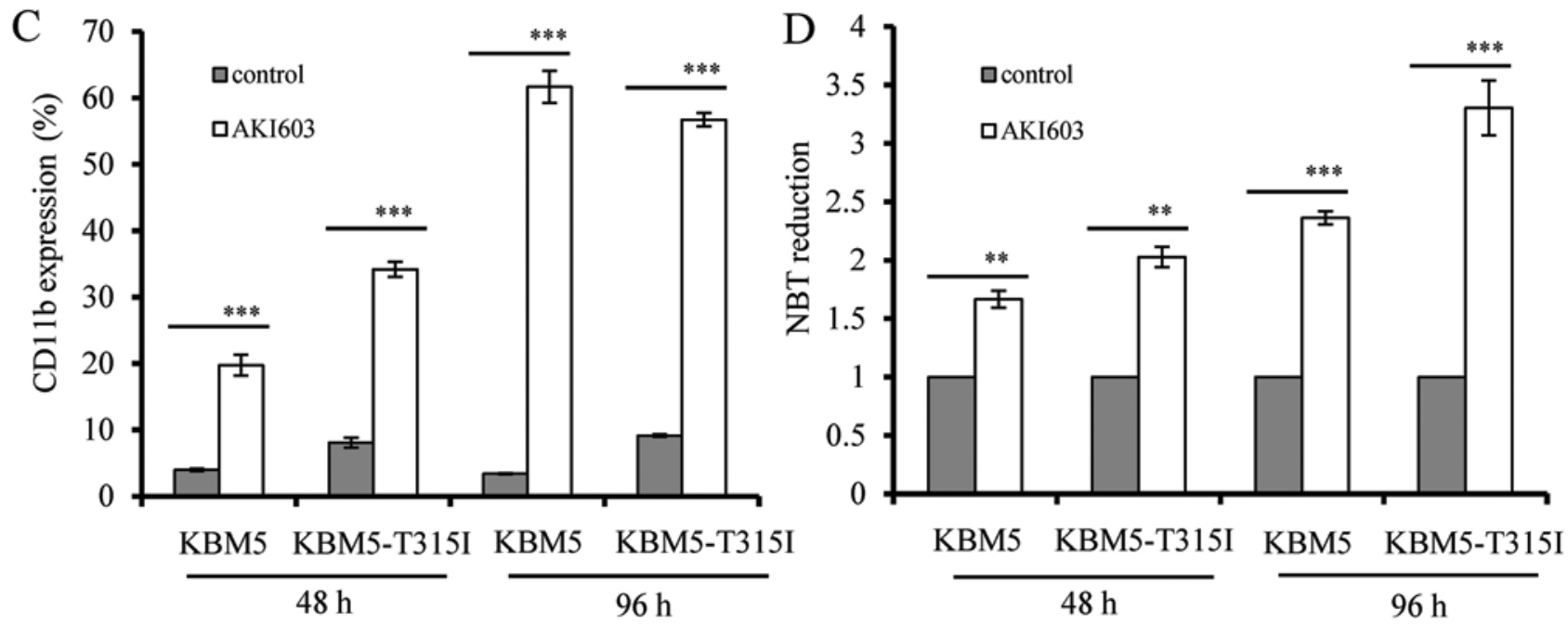

Figure 5. AKI603 promotes cell differentiation in CML cells. (A) Wright-Giemsa staining images of cells treated with $0.3125 \mu \mathrm{M}$ AKI603 for $96 \mathrm{~h}$ were captured by oil immersion lens (magnification, x1,000). (B) Cells treated with AKI603 for 48 or $96 \mathrm{~h}$ were subjected to flow cytometry of CD11b expression. Representative images are shown. (C) The statistical analysis of CD11b expression is presented as a bar graph. The bar represents means \pm SD of three independent experiments $\left({ }^{* * *} \mathrm{p}<0.001\right.$, Student's t-test). (D) Cells were treated with the same conditions as (B). Then cells were subjected to NBT reduction assay. The results are presented as a bar graph. The bar represents means \pm SD of three independent experiments $\left({ }^{* *} p<0.01,{ }^{* * *} p<0.001\right.$, Student's $t$-test).

formation ability and promoted cell differentiation in both wild-type BCR-ABL and BCR-ABL-T315I mutant CML cells, suggesting a new approach to overcome imatinib resistance.

Aurora kinase regulated multiple critical mitotic processes. Disruption of Aurora kinase activity induces abnormal spindle pole organization, centrosome separation and chromosome congression (23). Ultimately, cells treated with Aurora kinase inhibitor undergo cell growth inhibition through the development of deleterious aneuploidy $(24,25)$. In this report, we found that AKI603 inhibited Aur-A kinase and presented anti-leukemia effects in KBM5 cells, as well as KBM5-T315I cells, suggesting a possible novel and potent target in treating imatinib-resistant CML. We clearly showed that AKI603 inhibited viability of CML cells (Fig. 1). At the dose range used, AKI603 inhibited Aur-A phosphorylation at Thr288 (Fig. 1). In addition, AKI603 treatment initially resulted in G2/M cell cycle arrest and significant degree of aneuploidy (Fig. 2), a typical phenotype of Aurora suppression (24). These data were consistent with our finding in AML and solid tumor cells that inhibition of Aurora induced cell cycle arrest, promoted polyploidy formation and inhibited cell proliferation (24-26). 
Drug resistance is a major hindrance for effective leukemic treatment. The mechanism of resistance is complicated, such as accelerated drug efflux, the activation of oncogene or inactivation of tumor suppressor gene, metabolic disturbance and leukemia stem cells (LSCs) enrichment. Previous reports showed that $\mathrm{CD} 4^{+} / \mathrm{CD} 38^{-}$leukemic precursors exhibited resistance to daunorubicin in comparison with the $\mathrm{CD} 34^{+} / \mathrm{CD} 38^{+}$blasts with highly expressed multidrug resistance genes (27). Our study reported that $\mathrm{CD} 34^{+}$leukemic progenitor cells displayed drug resistance resulting from high levels of Bcl-2 expression (28). These data indicated that leukemic progenitor cells largely contributed to clinical drug resistance. It has been reported that Aur-A was overexpressed in both primary AML cells and LSCs compared to normal hematopoietic stem cells (29-31). Our recent data showed that inhibition of Aur-A activity by AKI603 reduced $\mathrm{CD} 24^{\mathrm{Low}} / \mathrm{CD} 44^{\mathrm{High}} \mathrm{TICs}$, and mammosphere formation (17), indicating that Aur-A kinase activity was important for maintaining TICs population. In this study, we found that Aur-A was active in imatinib-resistant cells (Fig. 1), suggesting that imatinib resistance might result from Aur-A activation and be associated with LSCs enrichment.

Consistent with our recent finding that Aur-A inhibition increased the sensitivity of conventional chemotherapeutic drugs (17), previous studies indicated that Aur-A was critical for overriding cell cycle checkpoint in cancer, and therefore responsible for the chemoresistance $(32,33)$. Aurora kinase inhibitor CCT129202 increased the sensitivity of ABCB1/ABCG2 overexpressing cells and cancer stem-like cells to chemotherapeutics (34). Inhibition of Aur-A plus cytarabine treatment in LSCs resulted in increased cytotoxicity compared to cytarabine treatment alone (30). MLN8237, under investigation in multiple phase I and II studies, was active in resistant CML and significantly increased the efficacy of nilotinib treatment (35). Moreover, it reduced the formation of spheroids, attenuated the self-renewal of spheroid forming cells, and promoted cell differentiation (36). Notably, the Aurora inhibitor MK0457 and histone deacetylase inhibitor vorinostat combination was highly active against primary CD34 ${ }^{+} \mathrm{CML}$ cells and $\mathrm{Ba} / \mathrm{F} 3$ cells with $\mathrm{BCR}-\mathrm{ABL}$ mutations, such as T315I, E255K, and M351T (37). All these studies indicated that Aur-A activity might be a potent target to abolish LSCs, thus overcoming drug resistance. In the present study, we showed that cells treated with AKI603 did not undergo obvious apoptosis (Fig. 3). Importantly, AKI603 inhibited cell colony formation (Fig. 4) and promoted cells differentiation (Fig. 5) under a long time culture in imatinib-resistant CML cells, indicating AKI603 might shift leukemic progenitor cells to differentiated population, rather than induce cell death.

In conclusion, the present study unveiled a potential antileukemia function of the potential Aurora kinase inhibitor AKI603. We also presented a novel mechanism that inhibition of Aur-A kinase by AKI603 overcame drug resistance through promoting cell differentiation in CML cells, suggesting a novel strategy in leukemia treatment.

\section{Acknowledgements}

We thank Mr. Wen-Xing Lai, the members of Quentin Liu lab and Medical Research Center, The Third Affiliated Hospital, Sun Yat-sen University for their critical comments and tech- nical support. This study was supported by the National High Technology Research and Development Program of China (863 Program; no. 2015AA020926 to Z.-J. Long), the Science and Technology Project of Guangzhou (no. 2012J2200077 to Z.-J. Long), the Fundamental Research Funds for the Central Universities (no. 11ykpy37 to Z.-J. Long), the National Natural Science Foundation of China (no. 81130040 to Q. Liu) and the National Basic Research Program of China (973 Program; no. 2012CB967000 to Q. Liu).

\section{References}

1. Savona M and Talpaz M: Getting to the stem of chronic myeloid leukaemia. Nat Rev Cancer 8: 341-350, 2008.

2. Gesbert F, Sellers WR, Signoretti S, Loda M and Griffin JD: $\mathrm{BCR} / \mathrm{ABL}$ regulates expression of the cyclin-dependent kinase inhibitor p27 ${ }^{\text {Kipl }}$ through the phosphatidylinositol 3-kinase/AKT pathway. J Biol Chem 275: 39223-39230, 2000.

3. Lugo TG, Pendergast AM, Muller AJ and Witte ON: Tyrosine kinase activity and transformation potency of bcr-abl oncogene products. Science 247: 1079-1082,1990.

4. Danial NN and Rothman P: JAK-STAT signaling activated by Abl oncogenes. Oncogene 19: 2523-2531, 2000.

5. Airiau K, Mahon FX, Josselin M, Jeanneteau M, Turcq B and Belloc F: ABT-737 increases tyrosine kinase inhibitor-induced apoptosis in chronic myeloid leukemia cells through XIAP downregulation and sensitizes CD34(+)CD38(-)population to imatinib. Exp Hematol 40: 367-378, 2012.

6. Soliera AR, Mariani SA, Audia A, Lidonnici MR, Addya S, FerrariAmorotti G, Cattelani S, Manzotti G, Fragliasso V, Peterson L, et al: Gfi-1 inhibits proliferation and colony formation of p210BCR/ ABL- expressing cells via transcriptional repression of STAT5 and Mcl-1. Leukemia 26: 1555-1563, 2012.

7. Kantarjian HM, Talpaz M, Giles F, O'Brien S and Cortes J: New insights into the pathophysiology of chronic myeloid leukemia and imatinib resistance. Ann Intern Med 145: 913-923, 2006.

8. Shah NP: Loss of response to imatinib: mechanisms and management. Hematology Am Soc Hematol Educ Program: 183-187, 2005.

9. Bradeen HA, Eide CA, O'Hare T, Johnson KJ, Willis SG, Lee FY, Druker BJ and Deininger MW: Comparison of imatinib mesylate, dasatinib (BMS-354825), and nilotinib (AMN107) in an N-ethylN-nitrosourea (ENU)-based mutagenesis screen: high efficacy of drug combinations. Blood 108: 2332-2338, 2006.

10. Deguchi Y, Kimura S, Ashihara E, Niwa T, Hodohara K, Fujiyama Y and Maekawa T: Comparison of imatinib, dasatinib, nilotinib and INNO-406 in imatinib-resistant cell lines. Leuk Res 32: 980-983, 2008.

11. Meraldi P, Honda R and Nigg EA: Aurora kinases link chromosome segregation and cell division to cancer susceptibility. Curr Opin Genet Dev 14: 29-36, 2004

12. Marumoto T, Zhang D and Saya H: Aurora-A - a guardian of poles. Nat Rev Cancer 5: 42-50, 2005.

13. Cammareri P, Scopelliti A, Todaro M, Eterno V, Francescangeli F, Moyer MP, Agrusa A, Dieli F, Zeuner A and Stassi G: Aurora-A is essential for the tumorigenic capacity and chemoresistance of colorectal cancer stem cells. Cancer Res 70: 4655-4665, 2010.

14. Shi Y, Reiman T, Li W, Maxwell CA, Sen S, Pilarski L, Daniels TR, Penichet ML, Feldman R and Lichtenstein A: Targeting aurora kinases as therapy in multiple myeloma. Blood 109: 3915-3921, 2007.

15. Giles FJ, Cortes J, Jones D, Bergstrom D, Kantarjian H and Freedman SJ: MK-0457, a novel kinase inhibitor, is active in patients with chronic myeloid leukemia or acute lymphocytic leukemia with the T315I BCR-ABL mutation. Blood 109: 500-502, 2007.

16. Shah NP, Skaggs BJ, Branford S, Hughes TP, Nicoll JM, Paquette RL and Sawyers CL: Sequential ABL kinase inhibitor therapy selects for compound drug-resistant BCR-ABL mutations with altered oncogenic potency. J Clin Invest 117: 2562-2569, 2007.

17. Zheng FM, Long ZJ, Hou ZJ, Luo Y, Xu LZ, Xia JL, Lai XJ, Liu JW, Wang X, Kamran M, et al: A novel small molecule aurora kinase inhibitor attenuates breast tumor-initiating cells and overcomes drug resistance. Mol Cancer Ther 13: 1991-2003, 2014. 
18. Luo Y, Deng YQ, Wang J, Long ZJ, Tu ZC, Peng W, Zhang JQ Liu $Q$ and Lu G: Design, synthesis and bioevaluation of $\mathrm{N}$-trisubstituted pyrimidine derivatives as potent aurora A kinase inhibitors. Eur J Med Chem 78: 65-71, 2014.

19. Melo JV and Chuah C: Resistance to imatinib mesylate in chronic myeloid leukaemia. Cancer Lett 249: 121-132, 2007.

20. Branford S: Chronic myeloid leukemia: molecular monitoring in clinical practice. Hematology Am Soc Hematol Educ Program: pp376-383, 2007.

21. Nicolini FE, Hayette S, Corm S, Bachy E, Bories D, Tulliez M, Guilhot F, Legros L, MaloiselF, Kiladjian JJ, et al: Clinical outcome of 27 imatinib mesylate-resistant chronic myelogenous leukemia patients harboring a T315I BCR-ABL mutation. Haematologica 92: 1238-1241, 2007.

22. Soverini S, Colarossi S, Gnani A, Rosti G, Castagnetti F, Poerio A, Iacobucci I, Amabile M, Abruzzese E, Orlandi E, et al: Contribution of ABL kinase domain mutations to imatinib resistance in different subsets of Philadelphia-positive patients: by the GIMEMA Working Party on Chronic Myeloid Leukemia. Clin Cancer Res 12: 7374-7379, 2006

23. Carmena M and Earnshaw WC: The cellular geography of aurora kinases. Nat Rev Mol Cell Biol 4: 842-854, 2003.

24. Liu LL, Long ZJ, Wang LX, Zheng FM, Fang ZG, Yan M, Xu DF Chen JJ, Wang SW, Lin DJ, et al: Inhibition of mTOR pathway sensitizes acute myeloid leukemia cells to aurora inhibitors by suppression of glycolytic metabolism. Mol Cancer Res 11: 1326-1336, 2013.

25. Long ZJ, Xu J, Yan M, Zhang JG, Guan Z, Xu DZ, Wang XR, Yao J, Zheng FM, Chu GL, et al: ZM 447439 inhibition of aurora kinase induces Hep2 cancer cell apoptosis in three-dimensional culture. Cell Cycle 7: 1473-1479, 2008.

26. Xu DR, Huang S, Long ZJ, Chen JJ, Zou ZZ, Li J, Lin DJ and Liu Q: Inhibition of mitotic kinase Aurora suppresses Akt-1 activation and induces apoptotic cell death in all-trans retinoid acid-resistant acute promyelocytic leukemia cells. J Transl Med 9: 74, 2011

27. Costello RT, Mallet F, Gaugler B, Sainty D, Arnoulet C, Gastaut JA and Olive D: Human acute myeloid leukemia CD34+ CD38 progenitor cells have decreased sensitivity to chemotherapy and Fas-induced apoptosis, reduced immunogenicity, and impaired dendritic cell transformation capacities. Cancer Res 60: 4403-4411, 2000.

28. Rao J, Xu DR, Zheng FM, Long ZJ, Huang SS, Wu X, Zhou WH, Huang RW and Liu Q: Curcumin reduces expression of Bcl-2, leading to apoptosis in daunorubicin-insensitive $\mathrm{CD} 34^{+}$acute myeloid leukemia cell lines and primary sorted CD34 ${ }^{+}$acute myeloid leukemia cells. J Transl Med 9: 71, 2011.
29. Yang J, Ikezoe T, Nishioka C, Nobumoto A, Udaka K and Yokoyama A: $\mathrm{CD} 34^{+} / \mathrm{CD} 38^{-}$acute myelogenous leukemia cells aberrantly express Aurora kinase A. Int J Cancer 133: 2706-2719, 2013.

30. Kim SJ, Jang JE, Cheong JW, Eom JI, Jeung HK, Kim Y, Hwang DY and Min YH: Aurora A kinase expression is increased in leukemia stem cells, and a selective Aurora A kinase inhibitor enhances Ara-C-induced apoptosis in acute myeloid leukemia stem cells. Korean J Hematol 47: 178-185, 2012.

31. Ye D, Garcia-Manero G, Kantarjian HM, Xiao L, Vadhan-Raj S Fernandez MH, Nguyen MH, Medeiros LJ and Bueso-Ramos CE: Analysis of Aurora kinase A expression in CD34(+) blast cells isolated from patients with myelodysplastic syndromes and acute myeloid leukemia. J Hematop 2: 2-8, 2009.

32. Ouchi M, Fujiuchi N, Sasai K, Katayama H, Minamishima YA, Ongusaha PP, Deng C, Sen S, Lee SW and Ouchi T: BRCA1 phosphorylation by Aurora-A in the regulation of $\mathrm{G} 2$ to $\mathrm{M}$ transition. J Biol Chem 279: 19643-19648, 2004.

33. Katayama H, Wang J, Treekitkarnmongkol W, Kawai H, Sasai K, Zhang H, Wang H, Adams HP, Jiang S, Chakraborty SN, et al: Aurora kinase-A inactivates DNA damage-induced apoptosis and spindle assembly checkpoint response functions of p73. Cancer Cell 21: 196-211, 2012.

34. Cheng C, Liu ZG, Zhang H, Xie JD, Chen XG, Zhao XQ, Wang F, Liang YJ, Chen LK, Singh S, et al: Enhancing chemosensitivity in ABCB1- and ABCG2-overexpressing cells and cancer stem-like cells by an Aurora kinase inhibitor CCT129202. Mol Pharm 9: 1971-1982, 2012

35. Kelly KR, Ecsedy J, Medina E, et al: The novel Aurora A kinase inhibitor MLN8237 is active in resistant chronic myeloid leukaemia and significantly increases the efficacy of nilotinib. J Cell Mol Med 15: 2057-2070, 2011.

36. Mohan P, Castellsague J, Jiang J, Allen K, Chen H, Nemirovsky O, Spyra M, Hu K, Kluwe L, Pujana MA, et al: Genomic imbalance of HMMR/RHAMM regulates the sensitivity and response of malignant peripheral nerve sheath tumour cells to aurora kinase inhibition. Oncotarget 4: 80-93, 2013.

37. Dai Y, Chen S, Venditti CA, Pei XY, Nguyen TK, Dent P and Grant S: Vorinostat synergistically potentiates MK-0457 lethality in chronic myelogenous leukemia cells sensitive and resistant to imatinib mesylate. Blood 112: 793-804, 2008. 